\title{
Indications of capsule endoscopy in Crohn's disease
}

\author{
Marisol Luján-Sanchis, Laura Sanchis-Artero, Patricia Suárez-Callol and Enrique Medina-Chulia \\ Department of Digestive Diseases. Consorcio Hospital General Universitario de Valencia. Valencia, Spain
}

\begin{abstract}
Capsule endoscopy currently plays a relevant role for Crohn's disease. This manuscript will discuss the current indications and practical uses of capsule endoscopy in this disease. It is a non-invasive technique that represents a significant advance in the endoscopic diagnosis of small bowel conditions. These circumstances, together with its diagnostic yield and excellent tolerability, make it considerably acceptable by both patients and physicians. This paper discusses the current evidence on the specific circumstances where capsule endoscopy may be indicated for three specific scenarios: Suspected Crohn's disease, indeterminate colitis, and established Crohn's disease, where it plays an extensive role. Furthermore, the impact and implications of capsule endoscopy results for follow-up are reviewed. These recommendations must be interpreted and applied in the setting of the integral, individual management of these patients. Understanding its appropriate use in daily clinical practice and an analysis of results may define endoscopic scoring systems to assess activity and mucosal healing in this condition. The present role of capsule endoscopy for Crohn's disease is subject to ongoing review, and appropriate usage uncovers novel applications likely to result in relevant changes for the future management of these patients.
\end{abstract}

Key words: Crohn's disease. Capsule endoscopy. Inflammatory bowel disease.

Luján-Sanchis M, Sanchis-Artero L, Suárez-Callol P, MedinaChulia E. Indications of capsule endoscopy in Crohn's disease. Rev Esp Enferm Dig 2014;106:37-45.

Received: $12-07-2013$

Accepted: 16-09-2013

Correspondence: Marisol Luján-Sanchis. Servicio de Patología Digestiva. Hospital General Universitario de Valencia. Avda. Tres Cruces, 2. 46014 Valencia, Spain

e-mail: marisol.lujan@ @otmail.es

\section{INTRODUCTION}

Early diagnosis in inflammatory bowel disease (IBD) currently remains a challenge given that inflammatory activity progression results in irreversible damage (1-4). Presently there is no reference test for the diagnosis of Crohn's disease (CD) $(5,6)$, hence techniques must be interpreted in an appropriate context (7). Until a decade ago endoscopic visualization of the small bowel (SB) mucosa was achieved by means of the limited reach of push enteroscopy or the invasive nature of intraoperative enteroscopy. Since receiving FDA approval in 2001, the use of capsule endoscopy (CE) has improved imaging diagnosis for SB diseases. It uses a small device that takes hundreds of photographs during its natural transit of the bowel, thus providing a direct, non-invasive view of the mucosa. This review discusses its primary indications for $\mathrm{CD}$ as based on currently available evidence (8-12). These publications highlight its value for the indentification of superficial lesions usually overlooked by other endoscopic and radiographic techniques $(7,9,12-15)$, and define it as the reference technique for SB assessment in the absence of strictures or fistulas $(12,16)$. Today, following bleeding of uncertain origin, $\mathrm{CD}$ is the second most important indication of CE (17). This review discusses its role in three scenarios: suspected $\mathrm{CD}$, indeterminate colitis, and established CD.

\section{DIAGNOSTIC CRITERIA USING CAPSULE ENDOSCOPY}

As with any endoscopic technique, the description of lesions consistent with CD uses a standardized terminology (18): Strictures, ulcers, erosions, aphthae, pseudopolyps, and fistulas (Fig. 1). In the presence of such lesions other conditions must be ruled out (infection, ischemia, vasculitis, iatrogenesis, tumors, lymphoma, and Behçet's 


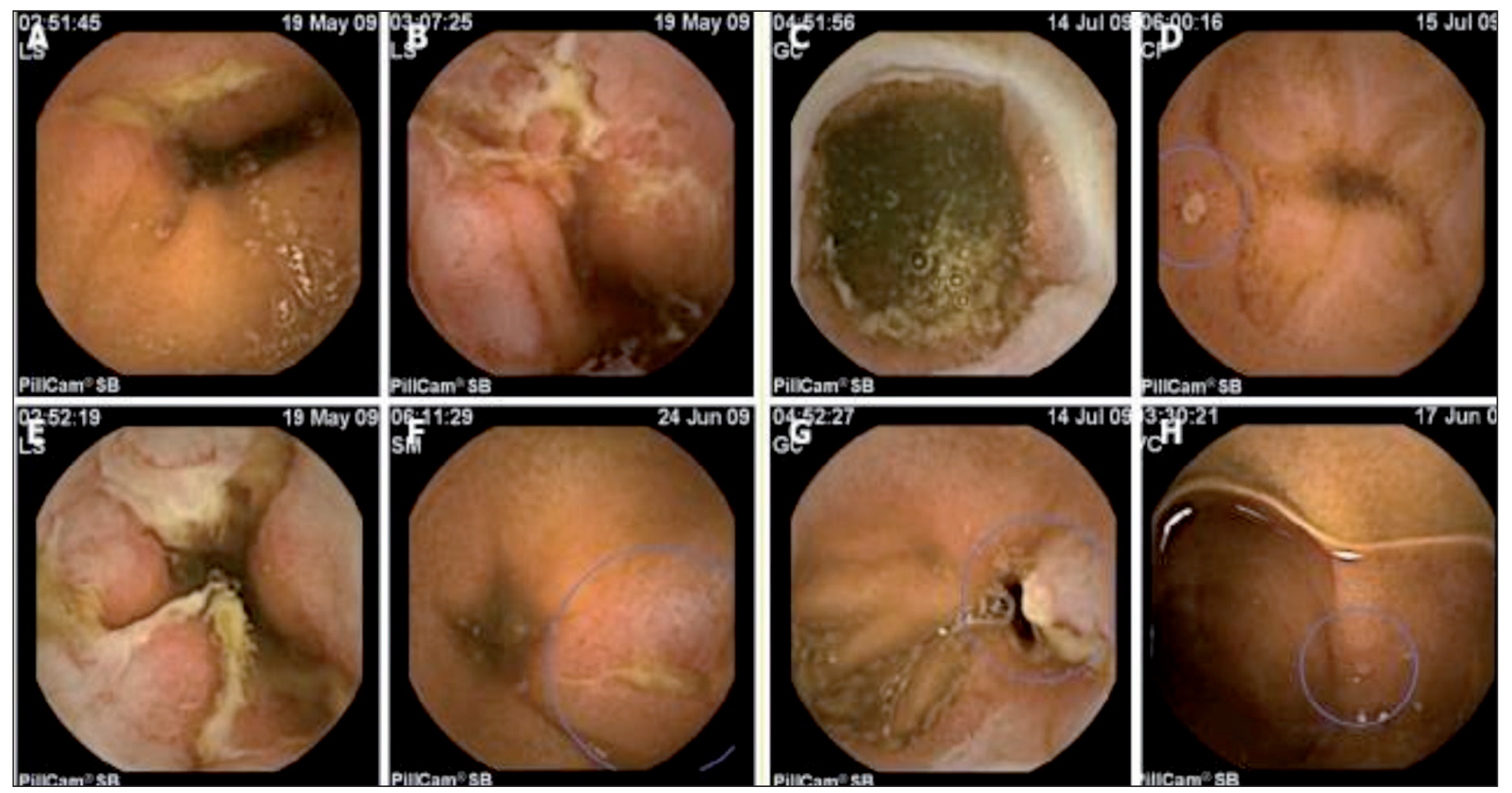

Fig. 1. The spectrum of lesions compatible with CD by capsule endoscopy: Aphthae, ulcers, ulcerated strictures, pseudopolyps.

disease, among others). Other lesions such as denudation, erythema or petechiae are considered nonspecific. Most studies have used the diagnostic criterion defined by Mow et al. (19) in 2004: Presence of diffuse or multiple -more than three- ulcerations in the absence of antiinflammatory drug ingestion. This criterion confers a sensitivity (S) of $77 \%$, a specificity (Sp) of $89 \%$, a positive predictive value (PPV) of $55 \%$, and a negative predictive value (NPV) of $96 \%$ for clinical, endoscopic, radiographic, and his- tological findings, hence it is highly relevant for disease exclusion.

Similarly, albeit with a lower specificity, the presence of multiple aphthous or erosive lesions ( $>10$ similar to those shown in figure 2), either with continuous or segmentlike distribution, has also been described as a diagnostic criterion for CD by other authors (20). In 2008, Gal et al. (21) reported on the capsule endoscopy-related CD activity index (Niv score or CECDAI), which defines ulcer size,

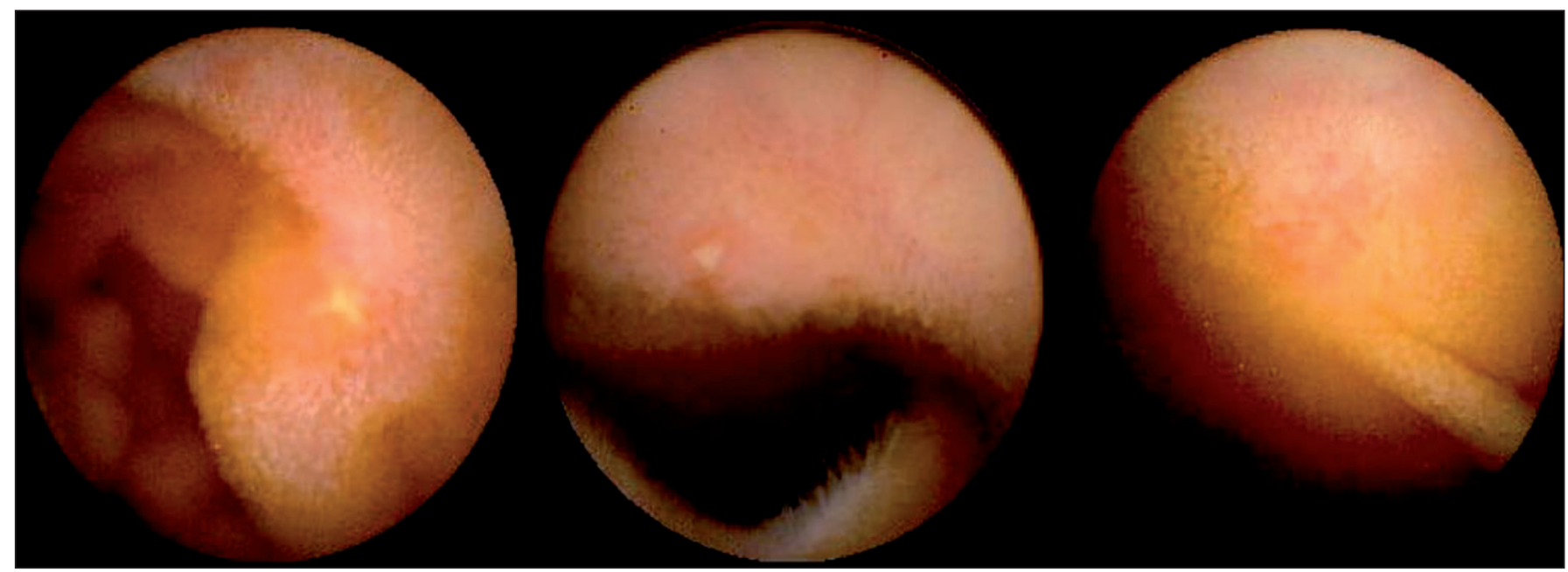

Fig. 2. Aphthous erosions detected by capsule endoscopy (8): The capsule may detect superficial intestinal lesions in a patient with Crohn's disease that are overlooked by radiographic techniques and inaccessible to ileocolonoscopy. 
extension, and strictures in the proximal and distal segments of the SB, and has been prospectively validated of late (22) (Table I). As is the case with colonoscopy, SB activity shows no clinical correlation. Thus, in a symptomatic patient, $\mathrm{CE}$ will detect lesions on half occasions $(23,24)$ and, vice versa, CE will identify lesions in $62 \%$ of patients in clinical remission $(\mathrm{CDAI}<150)(25)$.

\section{CE INDICATIONS IN CROHN'S DISEASE}

The role of capsule endoscopy in CD varies depending on suspicion earliness and on disease extension, activity and distribution $(26,27)$.

- Suspected Crohn's disease. CD suspicion is based on the occurrence of symptoms whether associated or otherwise with compatible extraintestinal manifestations, laboratory abnormalities, and/or radiographic findings (7). In such cases an ileocolonoscopy with biopsy taking should be performed, and an assessment of the proximal gastric and/or intestinal extension is advisable regardless of results $(5,12,28)$. Therefore, this is the second most important indication of CE in the adult (17), and the first mort important one in children from 10 to 18 years of age (29). Cost-effectiveness is greater when symptoms are accompanied by anemia, thrombocytosis, inflammation markers and/or fecal markers (30-33). Furthermore, this is a first-line technique when endoscopy and radiology results are negative or inconclusive, as it identifies subtle inflammatory changes usually overlooked by radiographic techniques (Fig. 2). Thus, two significant meta-analyses $(34,35)$ show performance to be superior to that of ileocolonoscopy, barium small-bowel follow-through (SBFT), and computed tomography (CT) by $22 \%, 37 \%$, and $42 \%$, respectively. Interestingly, studies comparing all the techniques used for the diagnosis of $\mathrm{CD}$ obtain highly variable results depending on the reference technique considered. Thus, when ileoscopy is the reference test $\mathrm{CE}$ show a value superior to that of computed tomography enterography (CTE) or magnetic resonance enterography (MRE) (36). In contrast, when enteroscopy plus expert clinical assessment is the reference test chosen, MRE is slightly superior to CE (37).

- Indeterminate colitis. Population-based studies have shown that in 4-10\% of patients with IBD and colonic involvement alone $\mathrm{CD}$ differentiation from ulcerative colitis is challenging. This condition is designated indeterminate colitis (IC) or IBD unclassified (IBDU) (38-40). In such cases CE may identify distal ileal lesions consistent with CD in 17-70\% of patients (40), with performance being superior to that of SBFT or enteroclysis. No data comparing CTE or MRE are available. Furthermore, when CE is normal, a future diagnosis (12) may not be excluded and a repeat CE may be recommended in the mid term (8).
Table I. Capsule endoscopy Crohn's disease activity index (CECDAI) (22)

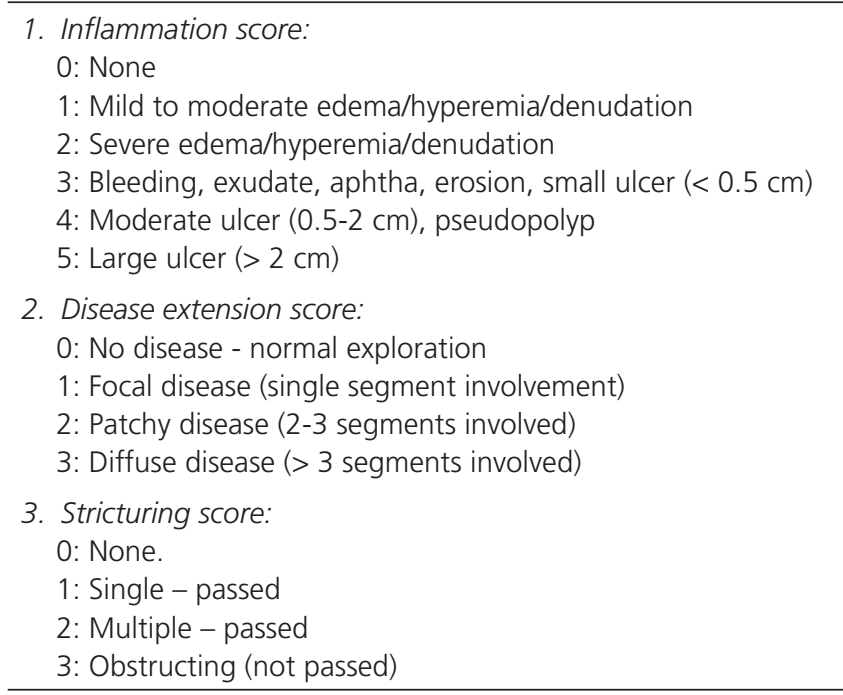

Segmentary score (proximal or distal): $(A \times B)+C$

Total score: proximal $([A \times B]+C)+\operatorname{distal}([A \times B]+C)$

- Established Crohn's disease. CE should be mainly considered when a change in disease management is foreseen $(6,8,9,28)$. Furthermore, given its high diagnostic yield for established disease $(85.7 \%)$, its findings may influence management changes and clinical monitoring in $64 \%$ of these patients (41). Therefore, in the presence of symptoms or signs unexplained by a normal or inconclusive result from radiology and/or colonoscopy, CE may detect lesions accounting for manifestations beyond the duodenum and terminal ileum, otherwise inaccessible to conventional endoscopy $(12,42)$. In addition, it may be advisable for unfeasible or normal ileocolonoscopies (28). In these indication, identification of mucosal lesions is superior versus SBFT (78 vs. $32 \%$ ) and may be better than with CTE (68 vs. $38 \%$ ) or MRE (93vs. $79 \%)$, but the clinical significance of such differences remains undefined.

\section{Assessment of extension in Crohn's disease}

Following full SB accessibility using CE, SB involvement was seen to potentially coexist with ileal and colonic disease. Because of this, the Vienna classification was replaced by the Montreal classification in 2005, adding the intestinal localization (L4) to the rest of sites when upper digestive tract involvement is detected to the proximal ileum (43). Half of patients with symptomatic ileal and/or colonic CD also have their proximal SB affected, with most common distributions including the proximal ileum (67\%) followed by the jejunum (53\%) and/ 
Table II. Lewis score for mucosal inflammatory changes (adapted from 58)

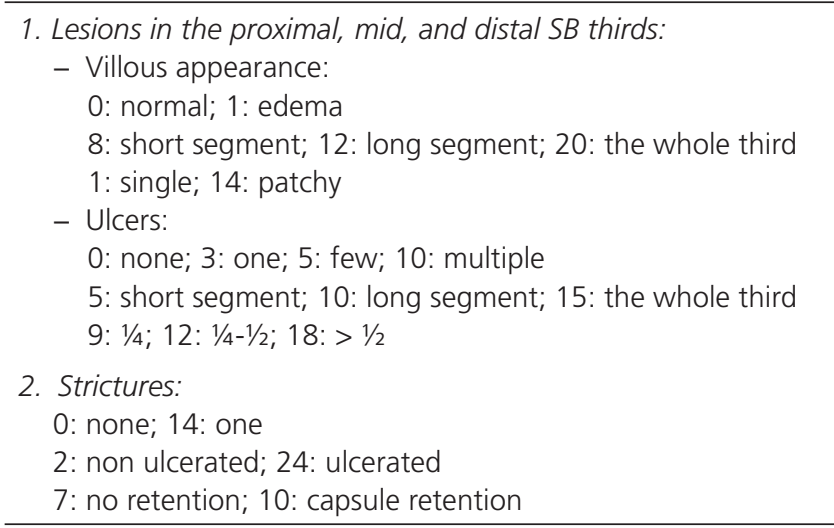

Score calculation: stricture score is added to the sum total for highest scoring villous edema and segment ulcers.

or duodenum $(32 \%)(23,44)$. Currently, an assessment of extension all along the GI tract is advisable at initial diagnosis $(12,45)$. Furthermore, very recent studies show that proximal involvement is associated with younger age, nonsmoking status, coexistence of ileal involvement, and stenosing pattern. Specifically, jejunal involvement is associated with stenosing patterns requiring more surgery $(46,47)$. Data are similar for CD with ileal involvement, which progresses towards stenosing and penetrating patterns more often than colonic CD (48). The association of stenosing behavior and jejunal CD may solely be the result of inflammatory response in the intestinal segment with the smallest lumen. In this respect the difference in stenosing complication rates between small-bowel and colonic CD seems logical.

\section{Crohn's disease in the small bowel}

Diagnosing CD only in the SB is truly challenging and the condition may occur in up to one third of patients (4951). Symptoms are usually nonspecific and, as with colonic involvement, bear little correlation to endoscopic activity. Screening modalities are currently considered supplementary, and their selection will depend upon experience in each individual site (52):

CE may provide early diagnosis for mucosal lesions and suggests the need for other exams (indication, biopsy, therapy, approach). Main benefits include absence of invasivity and radiation, direct study of the mucosa throughout the SB, and assessment of SB activity when ileocolonoscopy is normal. In the presence of stenosis CE is contraindicated. Given the low sensitivity of SBFT for stricture identification, its use is controversial (53). Thus, in most cases of capsule retention in patients with CD radiology was deemed inadequate to raise suspicion on potential ste- noses (54). Therefore, when stenosis is suspected, some authors recommend that a biodegradable capsule be previously used to assess potential CE contraindication (as discussed under "Complications").

Fecal calprotectin (FC) reveals in a noninvasive, direct manner activity or recurrence, and drives the need for other tests. It is well correlated to CE results, with $\mathrm{S}=83 \%, \mathrm{Sp}$ $=100 \%, \mathrm{PPV}=100 \%$, and NPV $=80 \%$ (24). Therefore, in patients with clinically suspected $\mathrm{CD}$ and a normal ileocolonoscopy, an FC value around $200 \mu \mathrm{g} / \mathrm{g}$ is associated with a high diagnostic yield by CE (65\%) (55).

CTE and MRE assess the progression of transmural damage and complications (transmural extension, abscesses, fistulas, stenoses, and collections), hence they are used prior to $\mathrm{CE}$ when such lesions need to be identified (8). Mucosal lesion detection using radiographic techniques is limited (56), although some series comparing MRE and CE find similar sensitivities (75\% vs. $77.8 \%$, respectively) (57).

\section{Assessing activity and severity}

CE allows to assess the whole SB and is activity. It is carried out for anemia, thrombocytosis, weight loss, and fecal inflammatory markers not justified by ileocolonoscopy or radiography findings $(26,28)$. Lesion severity is objectively assessed using reproducible scoring systems such as CECDAI (22) or Lewis score (58). CECDAI has no specific threshold but increased values indicate increased mucosal inflammation severity. Lewis score, in turn, assesses villous edema, ulcers, and strictures (Table II), with PPV $=82.6 \%, \mathrm{NPV}=87.9 \%, \mathrm{~S}=$ $82.6 \%$, and $\mathrm{Sp}=87.9 \%$ for the diagnosis of $\mathrm{CD}$ versus clinical, laboratory, radiographic, endoscopic, and histological assessment (59). Both scores are well correlated, with CECDAI levels of 3.8 and 5.8 corresponding to a Lewis score threshold of 135 and 790, respectively, the first values indicating mild activity and the second ones moderate-to-severe activity (60). Recently, other authors have identified a higher threshold of 23.5 in CECDAI for severe inflammation, which may be more useful for driving clinical management (61). These scores were initially developed to standardize capsule reports, but their use as a clinical tool needs prospective validation studies to assess CE-related lesion categorization systems (12). Hence, noninvasive studies such as radiology, FC, and CE must be considered supplementary (52).

Overall, the more suspicion criteria are available (clinical, laboratory, radiographic, endoscopic), the more likely will consistent lesions be found with CE. Thus, with 1 suspicion criterion $\mathrm{CE}$ reveals mild activity and diagnosis is confirmed in $20 \%$ of cases; however, with 3 suspicion criteria activity will be severe and diagnosis will be confirmed in around $80 \%$ of cases (59). Among healthy patients (no NSAID intake, intestinal resection, ankylosing spondylitis or digestive symptoms), only $9 \%$ may have 
mucosal lesions similar to those of CD; however, in all of them the Lewis score would suggest mild activity (62). These scores have shown a good correlation with FC, in such a way that LS is normal when $\mathrm{FC} \leq 100 \mu \mathrm{g} / \mathrm{g}(60)$. Therefore, when CD is suspected and endoscopy is normal, $\mathrm{FC}>100 \mathrm{mcg} / \mathrm{g}$ indicates CE (55), since FC elevation is similar for SB and colon inflammation (63).

\section{Assessing post-surgical recurrence}

Currently, the reference technique for this indication is ileoscopy using the Rutgeerts score (64). CE may identify proximal lesions out of ileoscopy's reach $(28,45,65)$, which may be classified using Buchmann's activity index (66). The management of recurrence (endoscopic followup and treatment) is determined by risk factors, among which extension in the SB stands out (67). It is recommended at 6 months or 1 year after surgery according to other associated risk factors (68). While the clinical relevance of findings has not been studied, CE has a sensitivity of $62-76 \%$ and specificity of $100 \%$ as compared to ileoscopy (8). It is indicated when endoscopy is contraindicated or unsatisfactory (28), and represents the test of choice for difficult-to-access anastomoses and to suit patient preferences (8).

\section{Mucosal healing}

Achieving deep remission (clinical, biological, mucosal healing) (3) improves prognosis in this disease. Mucosal healing is the initial event of suppressing inflammation in the deeper layers of the intestinal wall (69). Specifically, mucosal healing in the SN has been scarcely studied because of a lack adequate research tools. The use of CE for (non-fistulizing or penetrating) $\mathrm{CD}$ has shown ulcer improvement at 1 month after treatment (70). As is the case with colonic lesions, such healing does not correlate with clinical manifestations (71).

\section{Perianal disease}

Among patients with perianal disease who have a normal ileocolonoscopy, CE detects SB involvement in $24 \%$ of cases, prompting a change in management for them all. A positive $\mathrm{CE}$ is not associated with laboratory abnormalities, IBD family history, or age (72).

\section{Differential diagnosis with other intestinal conditions}

Other CE indications include intestinal tumor suspicion -as the relative risk for tumors is higher in IBD versus the general population $(73,74)$ - and malabsorption syndromes such as celiac disease and its complications (17). In uncertain celiac disease cases (negative antibodies and atrophy in the duodenal biopsy) $\mathrm{CE}$ has revealed lesions consistent with $\mathrm{CD}$ in $6 \%$ of patients (75).

\section{IMPACT OF CAPSULE ENDOSCOPY ON CROHN'S DISEASE}

Treatment changes brought about by CE include onset of a new therapy, medication changes or withdrawal, and surgery indication $(41,76,77)$. At a practical level this impact on CD management will depend on the reason why $\mathrm{CE}$ was indicated. Overall, CE performance for the diagnosis of CD in current publications is $60-85 \%(41,78)$. Similarly, CE results will result in changed decision-making for $90 \%$ of patients when ordered for suspected CD, for $88 \%$ of indeterminate colitis cases, and in $73 \%$ of subjects with known CD.

This impact is particularly relevant at pediatric ages since $\mathrm{CE}$ reclassifies as CD $50 \%$ of ulcerative colitis and IC cases, detects proximal lesions unnoticed by other techniques in $50 \%$ of subjects, and changes therapeutic decisions for $78 \%$ of patients (76).

Regarding established CD, therapeutic management will be modified in $64 \%$ of patients (41). In studies with over 900 patients with CD (77), $61.6 \%$ had their medication changed within 3 months following CE, and $39.5 \%$ received a new treatment. Disease findings by $\mathrm{CE}$, versus no or minimal findings, resulted in significant differences regarding therapy changes $(73.2 \%$ vs. $51.1 \%, \mathrm{p}=0.04)$, added medications (58.5\% vs. $22.2 \%, \mathrm{p}<0.01)$, and surgery indication $(21.9 \% v s .4 .4 \%, \mathrm{p}=0.01)$. On the other hand, these patients had their therapies changed (in the above percentages) when $\mathrm{CE}$ was indicated for anemia (60\%) and when disease extension needs to be assessed throughout the SB (58\%). However, when CE is ordered for discrepancies between clinical status and other (endoscopic, radiographic) testing, our attitude will only change for $20 \%$ of cases $(27,78)$.

\section{COMPLICATIONS}

The most relevant complication of CE, virtually the only one, is capsule retention, which is rare in this disease -the whole SB can be examined in $85.4 \%(79-90.8 \%)$ of patients (79). In patients with suspected CD the risk for retention is comparable to that of other indications, including occult bleeding (1.6\%); in subjects with established CD it is slightly higher (1.8-13\%), particularly in the presence of known intestinal strictures. Should intestinal stricturing be suspected, CE must be preceded by an intestinal patency test with the Patency biodegradable capsule (PC) (Given Imaging, Yoqneam, Israel), approved to this end by the FDA in 2006, or using radiology, according to local availability and site 


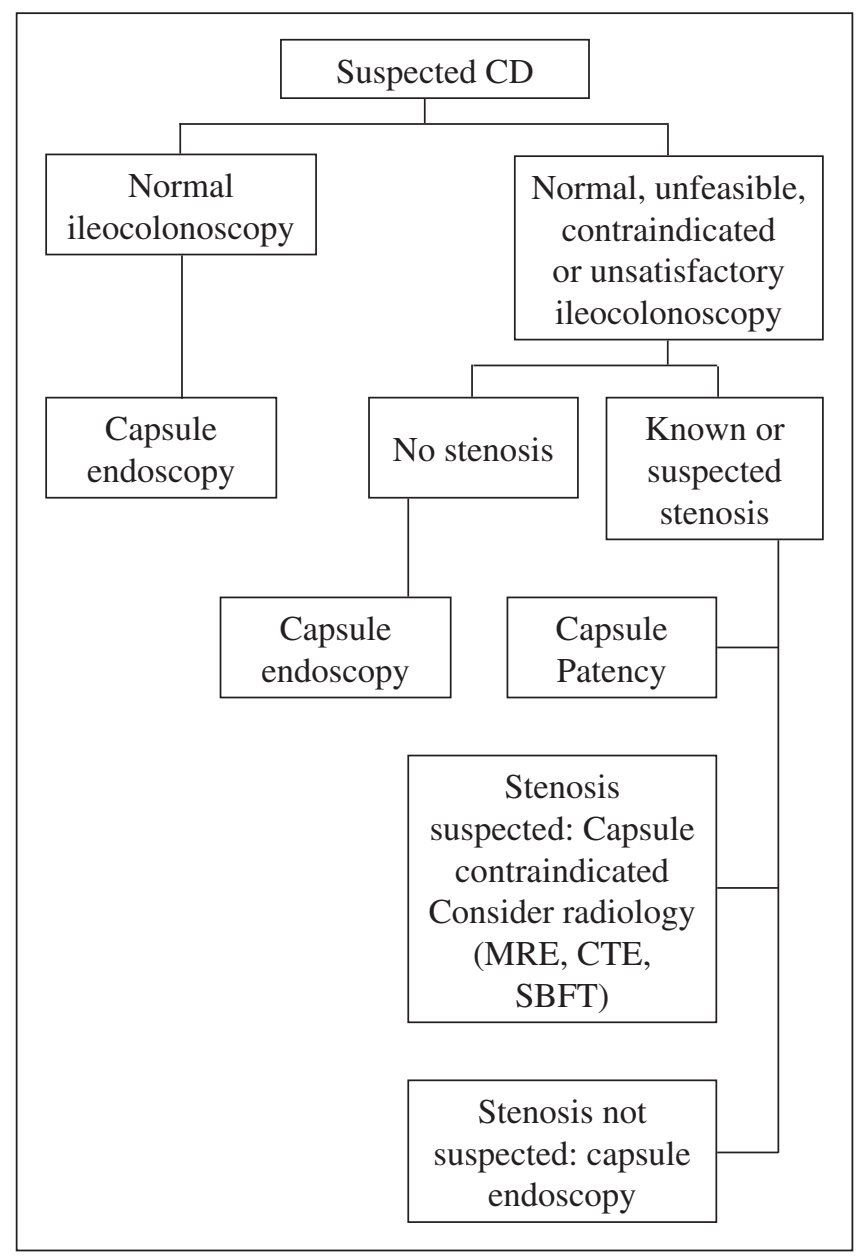

Fig. 3. A diagnostic protocol for suspected Crohn's disease (adapted from 84): When CD is suspected colonoscopy should be the first study to be performed, with capsule endoscopy ensuing when results are normal or unsatisfactory. If intestinal stenosis is suspected, a test capsule should be used to confirm the feasibility of capsule endoscopy.

expertise (12,80-82). PC or MRE will be chosen for pediatric patients as both exams are harmless at younger ages.

For some authors this is a "therapeutic" complication as it identifies strictures overlooked by other techniques and results in patient management changes (83). For this reason, in the presence of stricturing the $\mathrm{PC}$ may be administered beforehand and, if normally expelled, CE would not be contraindicated. Furthermore, it should be highlighted that a normal radiology does not fully exclude potential retention, hence PC is recommended for suspected strictures regardless of whether radiographic results are normal or otherwise. On the other hand, in the presence of a radiographically detected stricture (SBFT/CT) capsule retention will occur in only $21 \%$ of cases; therefore radiology should be avoided (particularly in younger patients) unless a patency test is abnormal (Fig. 3) (84).

Retention management will depend on stricture diameter and nature (85), and includes an expectant attitude while monitoring expulsion and medical or endoscopic treatment in the absence of complete obstruction, with surgery being indicated for the latter. Medical therapy includes laxative or steroid administration depending on retention etiology. Enteroscopy will be indicated for capsule recovery, stricture biopsy taking, and stricture dilation.

\section{CONCLUSIONS}

In summary, $\mathrm{CE}$ is a noninvasive technique with a widereaching role in $\mathrm{CD}$. Its main utility is well defined in the early diagnosis of mucosal lesions when this disease is suspected, to assess disease extension, and in the study of indeterminate colitis, particularly when management changes are involved. Endoscopic scoring systems exist that indicate disease activity in the SB, although their use should be extended in future prospective studies to define activity and mucosal healing criteria that might represent therapeutic guidelines. As with other diagnostic studies and current therapies, the role of all these CE applications in the modification of the natural history of this disease remains to be established.

\section{REFERENCES}

1. Cosnes J, Cattan S, Blain A, Beaugerie L, Carbonnel F, Parc R, et al. Long-term evolution of disease behavior of Crohn's disease. Inflamm Bowel Dis 2002;8:244-50.

2. Pariente B, Cosnes J, Danese S, Sandborn WJ, Lewin M, Fletcher JG, et al. Development of the Crohn's disease digestive damage score, the Lémann score. Inflamm Bowel Dis 2011;17:1415-22.

3. Panaccione R, Hibi T, Peyrin-Biroulet L, Schreiber S. Implementing changes in clinical practice to improve the management of Crohn's disease. J Crohn's Colitis 2012;6:S235-42.

4. Peyrin-Biroulet L, Loftus EV, Colombel JF, Sandborn WJ. Early Crohn disease: A proposed definition for use in disease-modification trials. Gut 2010;59:141-7.

5. Strange EF, Travis SPL, Vermeire S, Reinisch K, Geboes A, Barakauskiene A, et al. European evidence-based Consensus on the diagnosis and management of ulcerative colitis: Definitions and diagnosis. J Crohn's Colitis 2008;2:1-23.

6. Van Assche G, Dignass A, Panes J, Beaugerie L, Karagiannis J, Allez $\mathrm{M}$, et al. The second European evidence based consensus on the diagnosis and management of Crohn's disease: Definitions and diagnosis. J Crohn'sColitis 2010;4:7-27.

7. Mergener K, Ponchon T, Gralnek I, Pennazio M, de Franchis R, Seidman E, et al. Literature review and recommendations for clinical application of small-bowel capsule endoscopy, based on a panel discussion by international experts: Consensus statements for smallbowel capsule endoscopy, 2006/2007. Endoscopy 2007;39:895-909.

8. Bourreille A, Ignjatovic A, Aabakken L, Loftus EV, Eliaquim R, Pennazio $\mathrm{M}$, et al. Role of small-bowel endoscopy in the management of patients with inflammatory bowel disease: An international OMEDECCO consensus. Endoscopy 2009;41:618-37.

9. Ladas SD, Triantafyllou K, Spada C, Riccioni ME, Rey JF, Niv Y, et al. European Society of Gastrointestinal Endoscopy (ESGE): Recommendations (2009) on clinical use of video capsule endoscopy to investigate small-bowel, esophageal and colonic diseases. Endoscopy 2010;42:220-7.

10. Doherty GA, Moss AC, Cheifetz AS. Capsule endoscopy for smallbowel evaluation in Crohn's disease. Gastrointest Endosc 2011;74:16775 . 
11. Lucendo AJ, Guagnozzi D. Small bowel video capsule endoscopy in Crohn's disease: What have we learned in the last ten years? World J Gastrointest Endosc 2011;3:23-9.

12. Annese V, Daperno M, Rutter MD, Amiot A, Bossuyt P, Oriente J, et al. European evidence based consensus for endoscopy in inflammatory bowel disease. J Crohns Colitis 2013;7(12):982-1018.

13. Leighton JA, Shen B, Baron TH, Adler DG, Davila R, Egan JV, et al. Standards of Practice Committee. American Society for Gastrointestinal Endoscopy. ASGE guideline: Endoscopy in the diagnosis and treatment of inflammatory bowel disease. Gastrointest Endosc 2006;63:558-65.

14. Rey JF, Ladas S, Alhassani A, Kuznetsov K. European Society of gastrointestinal Endoscopy (ESGE). Video capsule endoscopy: update to guidelines (May 2006). Endoscopy 2006;38:1047-53.

15. Sidhu R, Sanders DS, Morris AJ, McAlindon ME. Guidelines on small bowel enteroscopy and capsule endoscopy in adults. Gut 2008;57:125-36.

16. Pohl J, Delvaux M, Ell C, Gay G, May A, Mulder CJJ, et al. European Society of Gastrointestinal Endoscopy (ESGE) Guidelines: Flexible enteroscopy for diagnosis and treatment of small-bowel diseases. Endoscopy 2008;40:609-61.

17. Early DS, Ben-Menachem T, Decker GA. Appropriate use of GI endoscopy. Gastrointest Endosc 2012;75:1127-3.

18. Delvaux M, Friedman S, Keuchel M, Hagenmüller F, Weinstein M, Cave D, et al. Structured terminology for capsule endoscopy: results of retrospective testing and validation in 766 small-bowel investigations. Endoscopy 2005;37:945-50.

19. Mow WS, Lo SK, Targan SR, Dubinsky MC, Treyzon L, Abreu-Martin MT, et al. Initial experience with wireless capsule enteroscopy in the diagnosis and management of inflammatory bowel disease. Clin Gastroenterol Hepatol 2004;2:31-40.

20. Voderholzer WA, Beinhoelzl J, Rogalla P, Murrer S, Schachschal G, Lochs H, et al. Small bowel involvement in Crohn's disease: A prospective comparison of wireless capsule endoscopy and computed tomography enteroclysis. Gut 2005;54:369-73.

21. Gal E, Geller A, Fraser G, Levi Z, Niv Y. Assessment and validation of the new capsule endoscopy Crohn's disease activity index (CECDAI). Dig Dis Sci 2008;53:1933-7.

22. Niv Y, Ilani S, Levi Z, Hershkowitz M, Niv E, Fireman Z, et al. Validation of the capsule endoscopy Crohn's disease activity index (CECDAI or Niv score): A multicenter prospective study. Endoscopy 2012;44:21-6

23. Mehdizadeh S, Chen GC, Barkodar L, Enayati PJ, Pirouz S, Yadegari M, et al. Capsule endoscopy in patients with Crohn's disease: diagnostic yield and safety. Gastrointest Endosc 2010;71:121-7.

24. De Cruz P, Kamm MA, Prideaux L, Allen PB, Moore G. Mucosal healing in Crohn's disease: A systematic review. Inflamm Bowel Dis 2013;19:429-44.

25. Aggarwal V, Day SD, Connor SJ, Leach ST, Brown GJ, Singh R, et al. Multicenter capsule endoscopy study of small bowel Crohn's disease patients in clinical remission: Long-term follow-up and correlation with faecal biomarkers and clinical outcome. Gastroenterology 2012;142(Supl. 1):169.

26. De Melo SW, Di Palma JA. The role of capsule endoscopy in evaluating inflammatory bowel disease. Gastroenterol Clin N Am 2012;41:315-23.

27. Dussault C, Gower-Rousseau C, Salleron J, Vernier-Massouille G, Branche J, Colombel JF, et al. Small bowel capsule endoscopy for management of Crohn's disease: A retrospective tertiary care centre experience. Dig Liver Dis 2013;45:558-61.

28. Papay P, Ignjatovic A, Karmiris K, Amarante H, Milheller P, Feagan B, et al. Optimising monitoring in the management of Crohn's disease: A physician's perspective. J Crohns Colitis 2013;7(8):653-69.

29. Fritscher-Ravens A, Scherbakov P, Bufler P, Torroni F, Ruuska T, Nuutinen $\mathrm{H}$, et al. The feasibility of wireless capsule endoscopy in detecting small intestinal pathology in children under the age of 8 years: A multicentre European study. Gut 2009;58:1467-72.

30. De Bona M, Bellumat A, Cian E, Valiante F, Moschini A, De Boni M, et al. Capsule endoscopy findings in patients with suspected Crohn's disease and biochemical markers of inflammation. Dig Liver Dis 2006;38:331-5.

31. Valle J, Alcántara M, Pérez-Grueso MJ, Navajas J, Munoz-Rosas C, Legaz ML, et al. Clinical features of patients with negative results from traditional diagnostic work-up and Crohn's disease findings from capsule endoscopy. J Clin Gastroenterol 2006;40:692-6.

32. Fidder HH, Nadler M, Lahat A, Lahav M, Bardan E, Avidan B, et al The utility of capsule endoscopy in the diagnosis of Crohn's disease based on patient's symptoms. J Clin Gastroenterol 2007;41:384-7.

33. Shim K-N, Kim Y-S, Kim K-J, Kim YH, Kim TI, Do JH, et al. Abdominal pain accompanied by weight loss may increase the diagnostic yield of capsule endoscopy: A Korean multicenter study. Scand J Gastroenterol 2006;41:983-8.

34. Triester SL, Leighton JA, Leontiadis GI, Gurudu SR, Fleischer DE, Hara AK, et al. A meta-analysis of the yield of capsule endoscopy compared to other diagnostic modalities in patients with non-stricturing small bowel Crohn's disease. Am J Gastroenterol 2006;101:954-96.

35. Dionisio PM, Gurudu SR, Leighton JA, Leontiadis GI, Fleischer DE, Hara AK, et al. Capsule endoscopy has a significantly higher diagnostic yield in patients with suspected and established small bowel Crohn's disease: A meta-analysis. Am J Gastroenterol 2010;105:1240-8.

36. Jensen MJ, Nathan T, Rafaelsen SR, Kjeldsen J. Diagnostic accuracy of capsule endoscopy for small bowel Crohn's disease is superior to that of MR enterography or CT enterography. Clin Gastroenterol Hepatol 2011;9:124-29.

37. Wiarda BM, Mensink PB, Heine DG, Stolk MD, Hazenberg H, Stoker J, et al. Small bowel Crohn's disease: MR enteroclysis and capsule endoscopy compared to balloon-assisted enteroscopy. Abdominal Imaging 2012;37:397-403

38. Vind I, Riis L, Jess T, Knudsen E, Pedersen N, Elkjaer M, et al. Increasing incidences of inflammatory bowel disease and decreasing surgery rates in Copenhagen City and County, 2003-2005: A population-based study from the Danish Crohn colitis database. Am J Gastroenterol 2006;101:1274-82.

39. Stewenius J, Adnerhill I, EkelundG, Florén CH, Fork FT, Janzon L, et al. Ulcerative colitis and indeterminate colitis in the city of Malmo, Sweden. A 25-year incidence study. Scand J Gastroenterol 1995;30:3843.

40. Mehdizadeh S, Chen G, Enayati PJ, Cheng DW, Han NJ, Shaye OA, et al. Diagnostic yield of capsule endoscopy in ulcerative colitis and inflammatory bowel disease of unclassified type (IBDU). Endoscopy 2008;40:30-3.

41. Lorenzo-Zúñiga V, de Vega VM, Domènech E, Cabré E, Mañosa M, Boix J. Impact of capsule endoscopy findings in the management of Crohn's disease. Dig Dis Sci 2010;55:411-4.

42. Bourreille A, Jarry M, D'Halluin PN, Ben-Soussan E, Maunoury V, Bulois $\mathrm{P}$, et al. Wireless capsule endoscopy versus ileocolonoscopy for the diagnosis of postoperative recurrence of Crohn's disease: A prospective study. Gut 2006;55:978-8.

43. Silverberg MS, Satsangi J, Ahmad T, ArnottI D, Bernstein CN, Bant $\mathrm{SR}$, et al. Toward an integrated clinical, molecular and serological classification of inflammatory bowel disease: Report of a Working Party of the 2005 Montreal World Congress of Gastroenterology. Can J Gastroenterol 2005;19(Supl. A):5-36.

44. Petruzziello C. Wireless capsule endoscopy and proximal small bowel lesions in Crohn's disease. World J Gastroenterol 2010;16:3299-304.

45. Baumgart D, Sandborn WI. Crohn's disease. The Lancet 2012;380:1590 605.

46. Lazarev M, Huang Ch, Bitton A, Cho JH, Duerr RH, McGovern DP, et al. Relationship between proximal Crohn's disease location and disease behavior and surgery: A cross-sectional study of the IBD genetics consortium. Am J Gastroenterol 2013;108:106-12.

47. Flamant M, Trang C, Maillard O, Sacher-Huvelin S, Le Rhun M, Galmiche JP, et al. The prevalence and outcome of jejunal lesions visualized by small bowel capsule endoscopy in Crohn's disease. Inflamm Bowel Dis 2013;19(7):1390-6.

48. Cosnes J. Epidemiology and natural history of inflammatory bowel diseases. Gastroenterology 2011;140:1785-94.

49. Molinie F, Gower-Rousseau C, Yzet T, Merle V, Grandbastien B, Marti $\mathrm{R}$, et al. Opposite evolution in incidence of Crohn's disease and ulcerative colitis in Northern France (1988-1999). Gut 2004;53:843-8.

50. Lashner B. Clinical features, laboratory findings, and course of Crohn's disease. In: Kirsner JV, editor. Inflamm Bowel Dis. 5th ed. Philadelphia: Saunders; 2000. p. 305-14.

51. Rameshshanker R, Arebi N. Endoscopy in inflammatory bowel disease when and why. WJ Gastrointest Endosc 2012;4:201-11. 
52. Gurudu SR, Leighton JA. Correlation of two capsule endoscopy scoring systems with fecal calprotectin: does it really matter? Dig Dis Sci 2012;57:827-9.

53. Cave D, Legnani P, de Franchis R, Lewis BS. ICCE consensus for capsule retention. Endoscopy 2005;37:1065-7.

54. Rondonotti E, Herrerias JM, Pennazio M, Caunedo A, MascarenhasSaravia M, de Franchis R. Complications, limitations and failures of capsule endoscopy: A review of 733 cases. Gastrointest Endosc 2005;62:712-6.

55. Koulaouzidis A, Douglas S, Rogers MA, Arnott ID, Plevris JN. Fecal calprotectin: A selection tool for small bowel capsule endoscopy in suspected IBD with prior negative bi-directional endoscopy. Scand J Gastroenterol 2011;46:561-6.

56. Costamagna G, Shah S, Riccioni M, Foschia F, Mutignani M, Perri V, et al. A prospective trial comparing small bowel radiographs and video capsule endoscopy for suspected small bowel disease. Gastroenterology 2002;123:999-1005.

57. Kovanlikaya A, Watson E, Hayward J. Beneck D, Sockolow R, Solomon A, et al. Magnetic resonance enterography and wireless capsule endoscopy in the evaluation of patients with inflammatory bowel disease. Clin Imaging 2013;37:77-82.

58. Gralnek IM, Defranchis R, Seidman E, Leighton JA, Legnani P, Lewis BS, et al. Development of a capsule endoscopy scoring index for small bowel mucosal inflammatory change. Aliment Pharmacol Ther 2008;27:146-54.

59. Rosa B, Moreira MJ, Rebelo A, Cotter J. Lewis score: A useful clinical tool for patients for suspected disease submitted to capsule endoscopy. J Crohn's Colitis 2012;6:692-7.

60. Koulaouzidis A, Douglas S, Plevris JN. lewis score correlates more closely with fecal calprotectin than capsule endoscopy Crohn's disease activity index. Dig Dis Sci 2012;57:987-93.

61. Holleran G, Hall B, Hussey M, Thornton O, Dobson M, McNamara D. How accurate are capsule endoscopy scoring systems in Crohn's disease? 8th Congress ECCO. 14-16 Feb 2013. Vienna Austria, Abstract P233.

62. Lewis JR, Pashinsky Y, Tindley A, Lewis BS. Capsule endoscopy in healthy individuals. Gastroenterology 2012;142:52-3.

63. Jensen MD, Kjeldsen J, Nathan T. Fecal calprotectin is equally sensitive in Crohn's disease affecting the small bowel and colon. Scand J Gastroenterol 2011;46:694-700.

64. Rutgeerts P, Geboes K, Vantrappen G,Beyls J, Kerremans R, Hiele $\mathrm{M}$, et al. Predictability of the postoperative course of Crohn's disease. Gastroenterology 1990;99:956-63.

65. Pons V, Nos P, Bastida G, Beltrán B, Argüello L, Aguas M, et al. Evaluation of postsurgical recurrence in Crohn's disease: A new indication for capsule endoscopy? Gastrointest Endosc 2007;66:533-40.

66. Buchman AL, Miller FH, Wallin A, Chowdhry AA, Ahn C. Videocapsule endoscopy versus barium contrast studies for the diagnosis of Crohn's. Am J Gastroenterology 2004;99:2171-7.

67. Buisson A, Chavauex JB, Bommelaer G, Peyrin-Biroulet L. Diagnosis, prevention and treatment of postoperative Crohn's disease recurrence. Dig Liver Dis 2012;44:453-60.

68. De Cruz P, Kamm MA, Prideaux L, Allen PB, Desmond PV. Postoperative recurrent luminal Crohn's disease: A systematic review. Inflamm Bowel Dis 2012;18:758-77.

69. Neurath MF, Travis SPL. Mucosal healing in inflammatory bowel diseases: A systematic review. Gut 2012;61:1619-35.
70. Tsibouris P, Periklis A, Chrissostomos K, Antonios Z, Panagiota M, Erasmia V, et al. When Crohn's disease is in remission, more patients complete capsule endoscopy study but less lesions are identifiedSaudi J Gastroenterol 2013;19(2):63-8.

71. Efthymiou A. Does clinical response correlate with mucosal healing in patients with Crohn's disease of the small bowel? A prospective, case-series study using wireless capsule endoscopy. Inflamm Bowel Dis 2008; $14: 1542-7$

72. Adler SN, Yoav M, Eitan S, Yehuda C, EliaKim R. Does capsule endoscopy have an added value in patients with perianal disease and a negative work up for Crohn's disease? World J Gastrointest Endosc 2012;4:185-8.

73. Jess T. Increased risk of intestinal cancer in Crohn's disease: A metaanalysis of population-based cohort studies. Am J Gastroenterol 2005:100:2724-9.

74. Canavan C. Meta-analysis: Colorectal and small bowel cancer risck in patients whit crohn's disease. Alimen Pharmacol Ther 2006;23:1097104.

75. Kurien M, Evans KE, Aziz I, Sidhu R, Drew K, Rogers TL, et al. Capsule endoscopy in adult celiac disease: a potential role in equivocal cases of celiac disease? Gastrointest Endosc 2013;77:227-32.

76. Gralnek IM, Cohen SA, Ephrath H, Napier A, Gobin T, Sherrod O, et al. Small bowel capsule endoscopy impacts diagnosis and management of pediatric inflammatory bowel disease: A prospective study. Dig Dis Sci 2012;57:465-71.

77. Long MD, Barnes E, Isaacs K, Morgan D, Herfarth HH. Impact of capsule endoscopy on management of inflammatory bowel disease: A single tertiary care center experience. Inflamm Bowel Dis 2011;17:1855-6.

78. Kalla R, McAlindon ME, Drew K, Sidhu R. Impact of capsule endoscopy on management in patients with established Crohn's disease experience from a single tertiary centre. Gut 2011;60:A216-17.

79. Liao Z, Gao R, Xu C, Li ZS. Indications and detection, completion, and retention rates of small-bowel capsule endoscopy: A systematic review. Gastrointest Endosc 2010;71:280-6.

80. Herrerías JM, Leighton JA, Costamagna G, Infantolino A, Eliakim R, Fischer D, et al. Agile patency system eliminates risk of capsule retention in patients with known intestinal strictures who undergo capsule endoscopy. Gastrointest Endosc 2008;67:902-9.

81. Saurin JC, Maunoury V, Lapalus MG, Cellier C, Delvaux M, Favre $\mathrm{O}$, et al. International consensus in Paris, 2006, on the indications and use of the endoscopic videocapsule test. Report of the SFED capsule commission. Gastroenterol Clin Biol 2007;31:798-805.

82. Postgate AJ, Burling D, Gupta A, Fitzpatrick A, Fraser C. Safety, reliability and limitations of the given patency capsule in patients at risk of capsule retention: A 3-year technical review. Dig Dis Sci 2008;53:2732-8.

83. Cheifetz AS, Lewis BS. Capsule endoscopy retention: Is it a complication? J Clin Gastroenterol 2006;40:688-91.

84. Leighton JA, Legnani P, Seidman EG. Role of capsule endoscopy in inflammatory bowel disease: Where we are and where we are going. Inflamm Bowel Dis 2007;13:331-7.

85. Cheon JH, Kim YS, Lee IS, Chang DK, Ryu JK, Lee KJ, et al. Can we predict spontaneous capsule passage after retention? A nationwide study to evaluate the incidence and clinical outcomes of capsule retention. Endoscopy 2007;39:1046-52. 